\title{
La vanguardia Bachueísta y los modos de ver el cuerpo en las artes de la primera mitad del siglo XX colombiano
}

\section{Artículo de reflexión}

\section{Ricardo Soler Rubio}

Estudiante de la Maestría en Estéticas Contemporáneas Latinoamericanas

Ciudad Autónoma de Buenos Aires, Argentina rasolerr@unal.edu.co

Recibido: 7 de abril de 2018

Aprobado: 4 de diciembre de 2018

Cómo citar este artículo: Soler Rubio, Ricardo (2019). La vanguardia Bachueísta y los modos de ver el cuerpo en las artes de la primera mitad del siglo XX colombiano. Calle 14: revista de investigación en el campo del arte 14(26). pp. 314-329. DOI: https://doi. org/10.14483/21450706.15006

\section{(c) (1)}

https://creativecommons.org/licenses/by/4.0/deed.es 


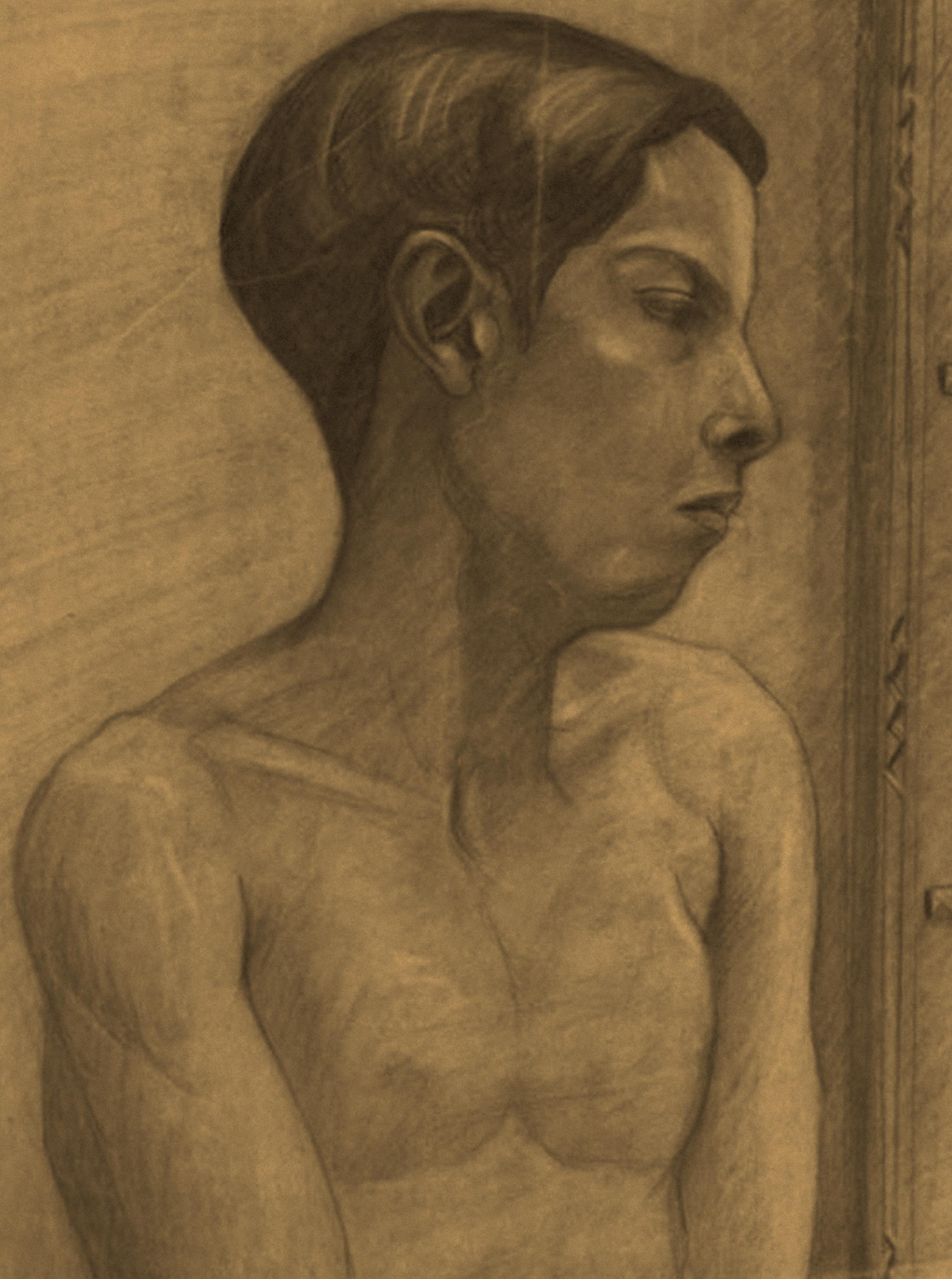


La vanguardia Bachueísta y los modos de ver el cuerpo en las artes de la primera mitad del siglo XX

colombiane

\title{
Resumen
}

Este texto propone dos momentos: primero, un breve recorrido de la coyuntura en la cual surge y es invisibilizado El Bachueísmo como movimiento artístico de vanguardia en Colombia; segundo, la revisión de algunas de las obras y trayectorias de los integrantes, en donde el cuerpo racializado — que en este movimiento ingresa al régimen de lo visible en el campo del arte- entra en tensión con los proyectos estéticos dominantes de la época a nivel nacional. Además, desde una lectura contemporánea se reflexiona sobre las conexiones del bachueísmo con el arte latinoamericano del mismo siglo, así como de la potencialidad de lo visual para interpelar el régimen estético colonial de la mirada que ha imperado históricamente en la academia de artes colombiana.

\section{Palabras clave}

Bachueísmo; arte moderno en Colombia; indigenismo; colonialidad; cuerpo

The Bachueísta Avant-garde and the Ways of Seeing the Body in the Arts of the First Half of the $20^{\text {th }}$ century in Colombia

\begin{abstract}
This article is composed of two moments: first, a brief tour of the conjuncture that saw Bachueísmo appear and then be made invisible as an avant-garde artistic movement in Colombia; second, a review of some of the works and trajectories of its members, at a time when the racialized body-entering the regime of the visible in the arts field-came into conflict with the dominant contemporary aesthetic projects at the national level. In addition, from a current day reading, we reflect on the connections of Bachueísmo with Latin American art of the early 20th century, as well as on the potentiality of the visual arts to question the colonial aesthetic regime on the gaze which has prevailed historically in Colombian academia.
\end{abstract}

\section{Keywords}

Bachueísmo; modern art in Colombia; indigenism; coloniality; body

L'avant-garde Bachueísta et les façons de voir le corps dans les arts de la première moitié du XXe siècle en Colombie

\section{Résumé}

Cet article est composé de deux moments : d'abord, une brève visite guidée de la conjoncture qui a vu l'apparition de Bachueísmo et ensuite son devenir invisible en tant que mouvement artistique avant-gardiste en Colombie ; deuxièmement, une analyse de certaines des œuvres et des trajectoires de ses membres, à un moment où le corps racialisé - entrant dans le régime du visible dans le champ des arts - est aussi entré en conflit avec les projets esthétiques contemporains dominants au niveau national. De plus, à partir d'une lecture actuelle, nous réfléchissons aux liens entre le Bachueísmo et l'art latino-américain du début du XXe siècle, ainsi qu'à la capacité des arts visuels à remettre en question le régime esthétique colonial sur le regard qui a prévalu historiquement dans le monde universitaire colombien.

\section{Mots clés}

Bachueísmo ; art moderne en Colombie ; indigénisme ; colonialité ; corps 


\section{Resumo}

Este artigo é composto por dois momentos: primeiro, um breve roteiro da conjuntura que viu Bachueísmo aparecer e depois tornar-se invisível como um movimento artístico de vanguarda na Colômbia; segundo, uma revisão de algumas das obras e trajetórias de seus membros, num momento em que o corpo racializado - entrando no regime do visível no campo das artes entrou também em conflito com os projetos estéticos contemporâneos dominantes em nível nacional. Além disso, a partir de uma leitura atual, refletimos sobre as conexões do Bachueísmo com a arte latino-americana do início do século XX, bem como sobre a potencialidade das artes visuais em questionar o regime estético colonial sobre o olhar que tem prevalecido historicamente em Academia colombiana.

\section{Palavras-chave}

Bachueísmo; arte moderna na Colômbia; indigenismo; colonialidade; corpo

\section{La vanguardia Bucheista i imasa kauangapa kuirpi artepe ñugpape iskai chunga unai uatakuna}

\section{Colombiape (siglo XX)}

\section{Maillallachiska}

Kai kilkaska churakume iskai momento, sugk mailla purii cuyunturapi llugsi i mana chi bachueismo kuiuri artístico vanguardia Colombiape, iskai, chi kauai sug ruraikuna i puriskakuna integrantekuna, chi kuirpupe racializado- chi kuiuriipi iaikume chi régimen kauari chi artepe iaiku uinjarichi proyecto estético mandadurkuna tukun Achka alpapi chimanda chi rimai kilkaskamanda contemporánea allilla iuiarii chi Bachueismomanda arte latinoamericananoa, chi unai uatamanda, chasallata kauangapa imasami kauarii auantaska antiua chi academia arte Colombiape.

\section{Rimangapa Ministidukuna}

Bachueismo; suma rurai musu Colombiape; nukanchi pura; colonialidad kuirpu 
"No se trata de saber quiénes somos sino, saber por fin en qué queremos convertirnos"

-Rosi Braidotti

Las artes visuales en Colombia, al igual que en variadas tradiciones latinoamericanas, lograron erigirse como un lugar hegemónico de producción estética e ideológica sobre los modos de representar y concebir el cuerpo en sus múltiples dimensiones: como manifestación de la subjetividad, como encarnación de las particularidades identitarias nacionales, como configuración del deseo que debe responder a ciertos paradigmas religiosos, pero también como espacio de disputa entre tipos de cuerpos que son jerarquizados social, política, religiosa, económica y estéticamente.

El campo de las artes, como un dominio de las élites nacionalistas en sus principios, no se distancia de los procesos de larga duración en el continente americano, como la invasión/colonización, la evangelización y exterminio de muchas de las comunidades preexistentes, la esclavitud, entre otros, produciendo una mirada moderno/colonial que se instaura en su momento como cultura afirmativa (y que aún continúa sus variantes y flujos) que aspira al establecimiento y naturalización de abstractos universales (para cada Estado nacional) a costa de la inconmensurable experiencia de la multiplicidad de cuerpos/subjetividades en concreta existencia.

Durante la primera mitad del siglo XX, los configurados Estados-Nación de América Latina y el Caribe, atraviesan por un proceso de cristalización de comunidades imaginadas a través de la intersección y potenciación de acontecimientos de diversa escala, entre ellos, la búsqueda e invención, desde las producciones estéticas, de culturas que pudieran instaurarse como propias y encubrir su artificio en cada territorio nacional para poder dar cuenta de un supuesto pasado en común, o proyectar a futuro una promesa de comunión patriótica.

En esta época, Latinoamérica y el mundo atravesaban fuertes coyunturas políticas que incidieron en los espacios de producción estética, logrando una fuerte resonancia en los proyectos de construcción de culturas afirmativas de las élites nacionales, que se apropiaron e hilaron discursos mistificados como hitos de la patria: el mestizaje y la revolución en las vanguardias mexicanas con el muralismo; el devoramiento de la cultura europea para la potenciación de lo propio en la antropofagia brasilera; o en la potencialidad arielista vista en los pueblos asentados en el Cono Sur.
Estas experiencias bordearon los procesos de consolidación identitaria a partir de la exaltación y jerarquización estética de ciertas perspectivas sobre los cuerpos: haciendo fluctuaciones entre subrayar lo mestizo como potencia epocal, legitimando subliminalmente proyectos eugenésicos de nación, esquivando cualquier reconocimiento a la multiplicidad en tensión permanente a lo largo y ancho del continente, ocultando las tensiones y contradicciones bajo el hibridismo sublimador.

Haciendo una lectura contemporánea de las manifestaciones estéticas de este periodo, Colombia también hizo eco en la producción estética ligada a la construcción de nación y de los cuerpos que la conforman. Sin embargo, uno de los proyectos vanguardistas iniciales, El Bachueísmo -inspirado en la diosa Bachué, generatriz de la cultura Muisca, cultura que habitó lo que sería el altiplano cundiboyacense, posterior territorio de la zona central y de la capital de la Nación colombiana - fue obliterado por el mismo devenir del campo artístico.

El trabajo poético que adelantó esta generación de artistas buscó rescatar y recrear lo "propio" a partir de la herencia indígena como fuente primigenia para construir el germen de lo nacional. Pese a no contar con un acervo significativo de obras conjuntas, sus integrantes - a mi modo de ver- lograron constituir una serie potente de obras de arte, entendidas como portadoras materiales de perceptos y afectos, que exceden a la agencia humana que los produjo, y en casos como el del escultor Rómulo Rozo, obras que trascendieron incluso su incidencia a nivel nacional.

En este texto se propone dos momentos: primero hacer un breve recorrido de la coyuntura en la cual surgen y son invisibilizados los Bachués como movimiento artístico de vanguardia en Colombia, para en segundo lugar abrir paso a una revisión de algunas de las obras y de sus integrantes, en donde el cuerpo racializado - que en este movimiento ingresa al régimen de lo visible en las artes - entra en tensión con los proyectos estéticos dominantes, con una respuesta ya antelada: su ocultamiento durante un largo periodo de la historia de las artes en Colombia, pero también, y para nuestro presente: una oportunidad de operar y crear genealogías de los cuerpos invisibilizados, racializados y blanqueados desde el campo estético, que hacen frente - a partir de sus resurgimientos y recreaciones - a los proyectos burgueses y (neo)colonialistas aún imperantes. Martin Jay, hace una acotación sintética como punto de partida de este escrito: 


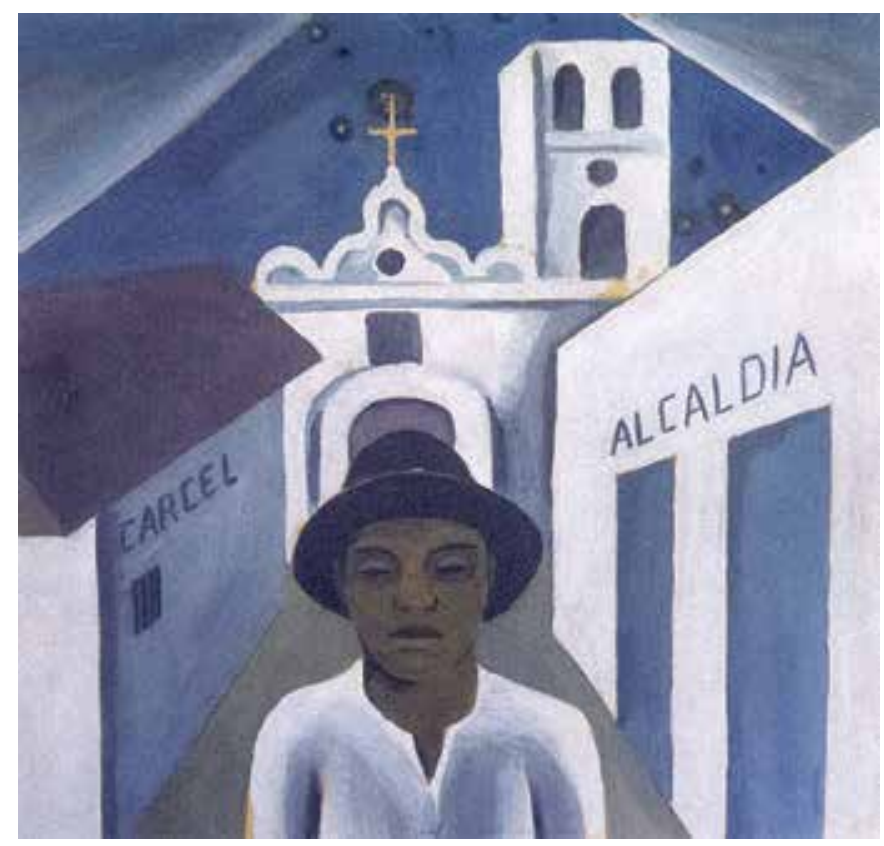

La educación estética en modo alguno fracasa; logra el mayor de los éxitos, hasta el punto de ocultar la violencia que la hace posible. Esa violencia está dirigida contra todos los impulsos culturales, especialmente aquellos presentes en el lenguaje, que se resisten a la totalización y la clausura obligados. (2003, p. 152)

\section{¿'Aceptar nuestra falta de pasado artístico"?}

El Bachueísmo surgió como un proyecto de consolidar una vanguardia artística que constituyera el arte nacional a partir de la recreación de las raíces amerindias de la nación. Se considera un punto de inflexión importante por la función que cumplió como detonante de polémicas en las artes plásticas colombianas desde los años treinta. Surgió como espacio aglutinante de varios artistas a partir de una serie de publicaciones periódicas en el suplemento dominical del diario El Tiempo en el año de 1930, en donde los escritores, novelistas y poetas Darío Achury Valenzuela, Rafael Azula Barrera, Darío Samper, Tulio González, Juan Pablo Varela y la escultora Hena Rodríguez Parra, produjeron un par de manifiestos colectivos retomando a la deidad muisca Bachué como una oportunidad de potenciar la experiencia y a la estética propias, para hacer frente al asimilacionismo academicista en las artes de la época:

La técnica de que se han valido nuestros pintores, y ésta es la segunda falsedad, no es técnica en la
Imagen 1. Sin Salida. (Gonzalo Ariza, 1935). Óleo sobre lienzo, 40 × 40 cm. Fuente: Gobernación de Antioquia (1998). Colombia en el Umbral de la Modernidad, un homenaje a los artistas antioqueños.

que se valga y se acentué la personalidad, el matiz propio, la característica diferencial, sino técnica imitada irreflexivamente, fórmulas académicas que ni siquiera se han purificado en el filtro de la emoción. Técnica de escuela española o francesa, que no ha sido enseñanza o escuela de la que se dedujera una orientación, sino simplemente, fría calcomanía, interpretación al través de las mismas fórmulas, fabricación y no creación. (Achury, 1930)

La serie de monografías/manifiestos publicados en los suplementos del diario El Tiempo, en su momento firmados colectivamente y luego continuados por algunos de los participantes, para 1930 detallan la apuesta por la consolidación de un arte nacionalista, vinculado a las luchas y movimientos estéticos que avanzan en América, apuntando incluso a una construcción nuestramericanista que buscaba de manera discutible trascender incluso las disputas antiimperialistas para lograr "una América que pueda ser consabida, sentida y disfrutada por todos los pueblos americanos" (Achury, 1930).

La agrupación se movilizó a partir del furor de la obra del escultor colombiano, Rómulo Rozo: Bachué, diosa generatriz de los muiscas, realizada en 1925, producto de la lectura de las Noticias historiales de las conquistas de Tierra Firme en las Indias Occidentales de Fray Pedro Simón relatando su llegada al altiplano cundiboyacense. Esta obra adquirió reconocimiento internacional tras su presentación en la Exposición Iberoamericana de 1929 en Sevilla, momento desde el cual se le atribuye a este escultor como hito del arte 
moderno -en términos de adquisición de relativa independencia estética- en Colombia.

Posterior al grupo inicial que gestó los manifiestos, algunos artistas se adhirieron al pensamiento y propuestas de retomar la historia y producciones locales, para proyectar una suerte de "nacionalismo latinoamericanista" como Luis Alberto Acuña, también influenciado por el muralismo mexicano. Este pintor tuvo una producción artística, así como de investigación de las artes en Colombia (y que posteriormente se reconoce como aporte a la etnomusicología, a la antropología y a la historiografía prehispánica) orientada a visibilizar las aportaciones y la existencia previa a la conquista de un legado artístico originado en el continente que habitamos.

Después de los artistas que directamente se vincularon o se reconocieron afines al Bachueísmo, algunos poco visibilizados o rescatados tardíamente trabajaron de manera singular la cuestión identitaria nacional y latinoamericana, en donde justamente, el cuerpo como lugar de representación de esa identidad deja marcaciones de lo racial y lo culturalmente diferencial a la cultura afirmativa nacional que se proyectó en distintos momentos como universal abstracto.

No corresponde extenderme acá a un análisis exhaustivo que desmerite escritos y tesis mucho más rigurosas sobre el bagaje de artistas colombianos que no acataron directamente un asimilacionismo o adiestramiento de la estética con pretensiones universalistas originada en los centros de poder moderno/coloniales, pero en aras de no pretender invisibilizar: Gonzalo Ariza, Ignacio Gómez Jaramillo, Alipio Jaramillo, Débora Arango, Josefina Albarracín y seguramente muchos y muchas más que por mi humana inhabilidad de dar cuenta de un panorama general, omito por ignorancia.

Pese a la fugacidad del movimiento de los Bachués como colectivo organizado y proyectado, su incidencia tuvo una trayectoria ambivalente para el arte colombiano, llegando a ser reconocida tardíamente y rescatada como hito de la modernidad artística en el país solamente hasta la finalización de las década de los 80 , pues desde sus comienzos recibió fuertes juzgamientos por parte de la crítica académica de las artes, cuestionamientos que provinieron en parte de la preminente figura de la crítica de artes colombo-argentina Marta Traba, lo que generó un rezago e invisibilización a la apertura estética hacia otras fuertes tanto técnicas como temáticas e incluso desestabilizadoras del régimen ocularcentrista que posibilitaría el movimiento de los Bachués y del que hablaré más adelante.

La polémica generada por la perspectiva de Traba $^{1}$, considerada una de las figuras centrales de la crítica de artes en el país, así como quien logró instaurar y proyectar internacionalmente a un grupo de jóvenes artistas como el hito del arte moderno en Colombia, ubica al movimiento de los Bachués así como a otros artistas afines al mismo, en un lugar leído contemporáneamente como fuera del canon ${ }^{2}$ moderno/colonial, en donde las aspiraciones de contribuir al arte "universal" — contemporáneamente con intereses de cosmopolitanismoque promulgaba Traba, la orientaban a catalogar al movimiento americanista (indigenista sí, pero también crítico y consciente del mestizaje en muchos casos) como nacionalismo bruto que demostraba la "incultura" (concepto acuñado por la mismísima Traba en su texto ya referenciado) de las naciones latinoamericanas del momento y que era incapaz de reconocer la maestría europea o la posición de "alumno ejemplar" que debía ocupar el que pretendiere ser artista local con aspiraciones globales.

Este ocultamiento se puede leer fatídicamente como consecuencia del inconsciente colonial instaurado en el pensamiento estético de la época (iy aún vigente!), sin desconocer el enorme aporte a las artes colombianas, el sesgo eurocéntrico de la crítica de artes no permitió reconocer en estas exploraciones de lo propio, un potencial de producción estética y poética de estos artistas, que igualmente, con posiciones privilegiadas en las configuraciones de clase de la época, intentaron cuestionar a modo de ensayo/error pero con trabajos

1 Sobre la polémica entre Marta Traba y los artistas que se afiliaron o identificaban con la propuesta bachueísta, hay un amplio recorrido recopilado detalladamente por el investigador de arte Christian Padilla en su libro La llamada de la tierra: El nacionalismo en la escultura colombiana. Bogotá: Fundación Gilberto Álzate Avendaño, 2008.

2 No estamos hablando justamente de producciones estéticas ajenas al campo de las artes institucionalizadas, aún no podemos dimensionar el salto para ampliar rigurosamente las discusiones estéticas latinoamericanas a otros lugares por fuera de los campos privilegiados de las artes académicas. Me interesa reconocer que hay avances en estas luchas por descolonizar el pensamiento y el accionar estético como lo proponen Walter Mignolo desde su propuesta teórica, Adolfo Albán Achinte desde los procesos de creación por encima del arte como institución, Ricardo Lambuley desde la música en lógicas no académicas de los pueblos afrodiaspóricos, José Jorge de Carvalho en su vinculación intercultural entre la academia y los saberes comunales o María Acaso con su llamado de atención sobre la educación artística más allá de las manualidades. 
rigurosos de investigación los cánones eurocéntricos inconsciente/incuestionablemente instaurados como universales.

El cuerpo ¿representado? en la obra de estos artistas, no solamente entraba en pugna estética con los cánones tradicionales y de vanguardia a nivel académico por sus técnicas o sus referentes, sino que en sentido amplio posibilitaron un régimen de visibilización y enunciación de corporalidades relegadas del ideal identitario - hecho cuerpo visible y descriptible- de la nación, así como permite ampliar y trabajar las nociones de cuerpo hegemonizadas a través de la institucionalidad del arte.

\section{El cuerpo por desestabilizar desde los trazados bachueístas}

La instauración de una élite burguesa con algunos miembros vocacionalmente orientados al campo artístico logró generar un entramado institucional (a partir del mecenazgo desde el siglo XIX pero también desde los gobiernos liberales del siglo XX) orientado a trabajar y consolidar una imagen relativamente estable y definida de la identidad nacional, proceso a través del cual se instauró un modelo compartido con varios países de la región pues no contábamos con suficientes migrantes e inversionistas europeos interesados en la Sur América supra ecuatorial, produciendo una suerte de resignación nacionalizable: el mestizaje como proyecto de nación impulsado por las élites económicas e intelectuales.

Independientemente de las recientes revisiones al concepto de mestizaje concebido como obliteración de conflictos raciales y epistemológicos que constituyeron los encuentros culturales en las américas (Rivera Cusicanqui, 2018), pretendiendo imponer un ideal resignado de una blanquitud inalcanzable en el proyecto nacional, el campo estético tradicional, imperante durante el siglo XIX estuvo particularmente afectado por las nociones de belleza universales a la época: los paradigmas técnicos y estilísticos, así como los estereotipos y creencias de lo que es bello -en este caso los tipos de cuerpos bellos- se vieron reflejados por completo en las producciones pictóricas desde las proclamaciones independentistas hasta bien entrado y continuado el siglo XX. Uno de los pintores canónicos de Colombia a inicios del siglo XX según la historia nacional de las artes, Francisco Antonio Cano, presenta uno de los cuadros icónicos de la identidad nacional para la academia y el mundo letrado: un retrato fidedigno de la colonización antioqueña.

La revisión de la historia de las artes en el país muestra un sin número de ejemplares de la población campesina, mestizada y de los sectores "populares" como gentes blancas. El siglo XX fue lugar de la proyección de la nación a futuro bajo las promesas de modernidad y desarrollo. Se ha logrado acoplar a los proyectos de la

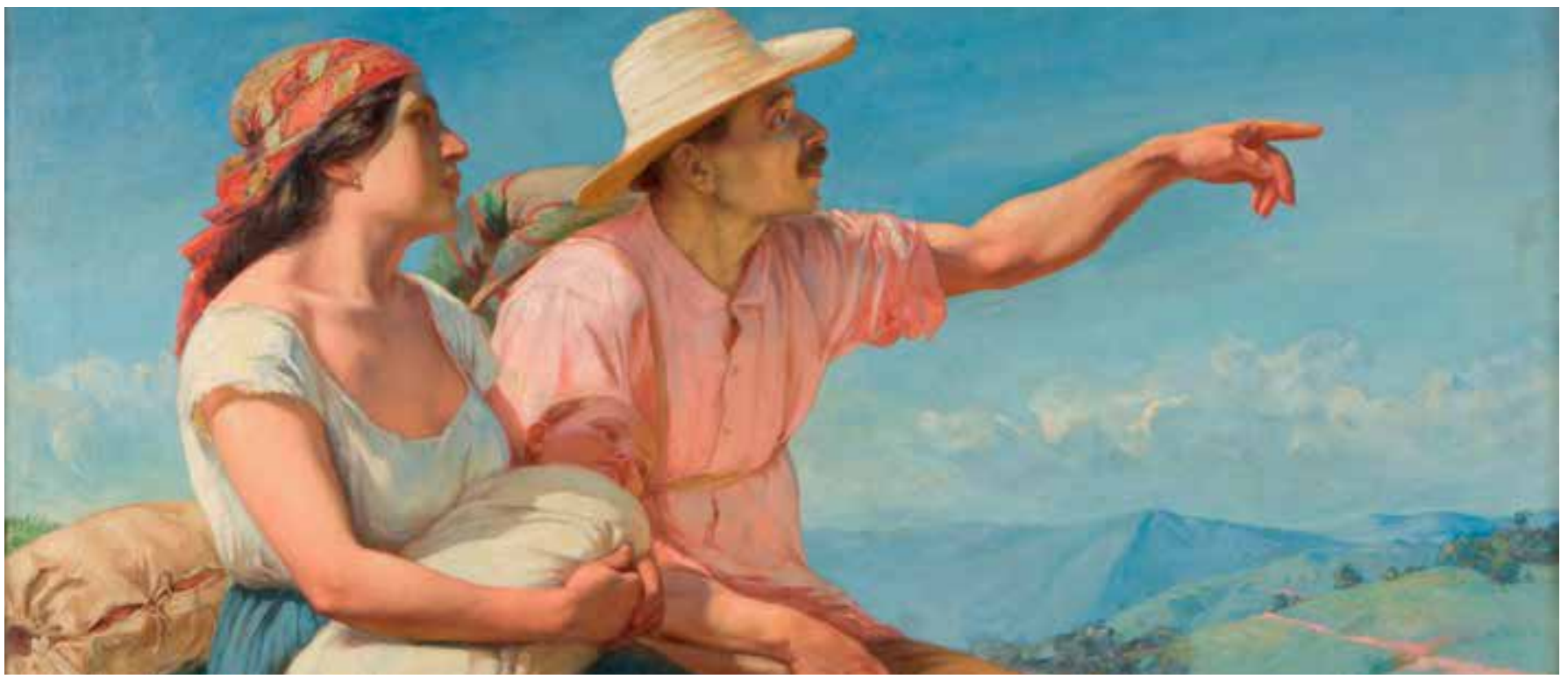

Imagen 2. Horizontes (fragmento). (Francisco Antonio Cano, 1913). Óleo sobre tela, 95 x $150 \mathrm{~cm}$. Fuente: página web del Museo de Antioquia. https://www.museodeantioquia.co/obra-del-mes/horizontes/ 


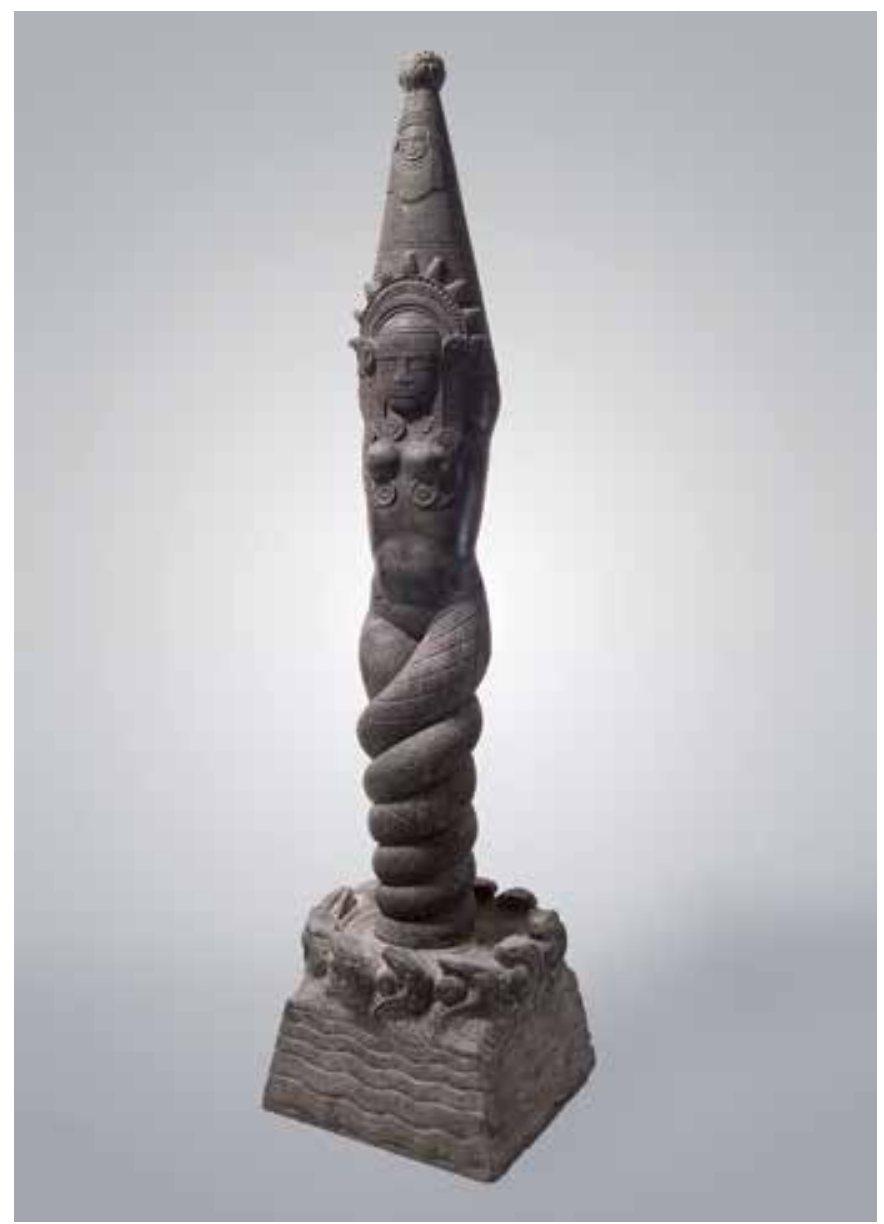

nación la producción de modos de ver que son estrictamente políticos, en donde la apuesta es clara. El cuerpo popular debe apelar a ciertos estándares de belleza, pero a su vez no pasa de ser el motor físico y portador del alma, la mera fuerza de trabajo a ser sacrificada para la constitución de una nación.

En este contexto la irrupción de los Bachués, más que innovación, crítica y propuesta programática, fue interpretada en su época como un estilo de arte retardatario, antiprogresista y carente de nivel estético. Los ataques provenientes de diversos frentes evidencian ahora (un poco tarde) la hegemonía de un ocularcentrismo orientado a la legitimación del orden colonial capitalista que se vuelve efectivo ante la inmediatez de las pinturas que construyeron los discursos de la nación, en donde el negro o el indio fueron males o sacrificios necesarios, mientras que el objetivo de un mestizaje lo más blanco posible queda claro en las imágenes que "nos" representan.

Ahora bien, los cuerpos que se trabajan y se muestran desde las obras y autores del movimiento sobrepasan por completo el indigenismo esencialista que aún hoy
Imagen 3. Bachué. Diosa Generatriz del pueblo chibcha. (Rómulo Rozo, 1925). Granito. Fuente: proyectobachue.org Cuaderno Bachué N.O.

se les adjudica: El cuerpo no es reducido al objeto, el recipiente del alma o la fuerza de trabajo para proyectar el futuro nacional. Es el lugar que cuestiona esas ideas, y es potente porque son cuerpos que muestran historia, y otras historias diferentes a las contadas desde los textos y manuales escolares o discursos políticos patriotistas.

El cuerpo en el arte nos permite orientar preguntas sobre la política colonial y clasista que se instauró como proyecto de Estado, pero trasciende por completo los márgenes relativamente consensuados de la macro política: nos deja entrever el nivel micropolítico de la estética como dispositivo biopolítico, como ideología:

Lo que se necesita, en cambio, es lo que Schiller llamó la 'modulación estética de la psique', que equivale a decir un proyecto vigoroso de construcción ideológica fundamental [...] El sujeto moderno es, entonces, más estético que cognitivo o ético; es el sitio de una conciliación internalizada pero ilusoria de demandas conflictivas, que permanecen frustrantemente en conflicto en el mundo social. (Jay, 2003, p. 155) 


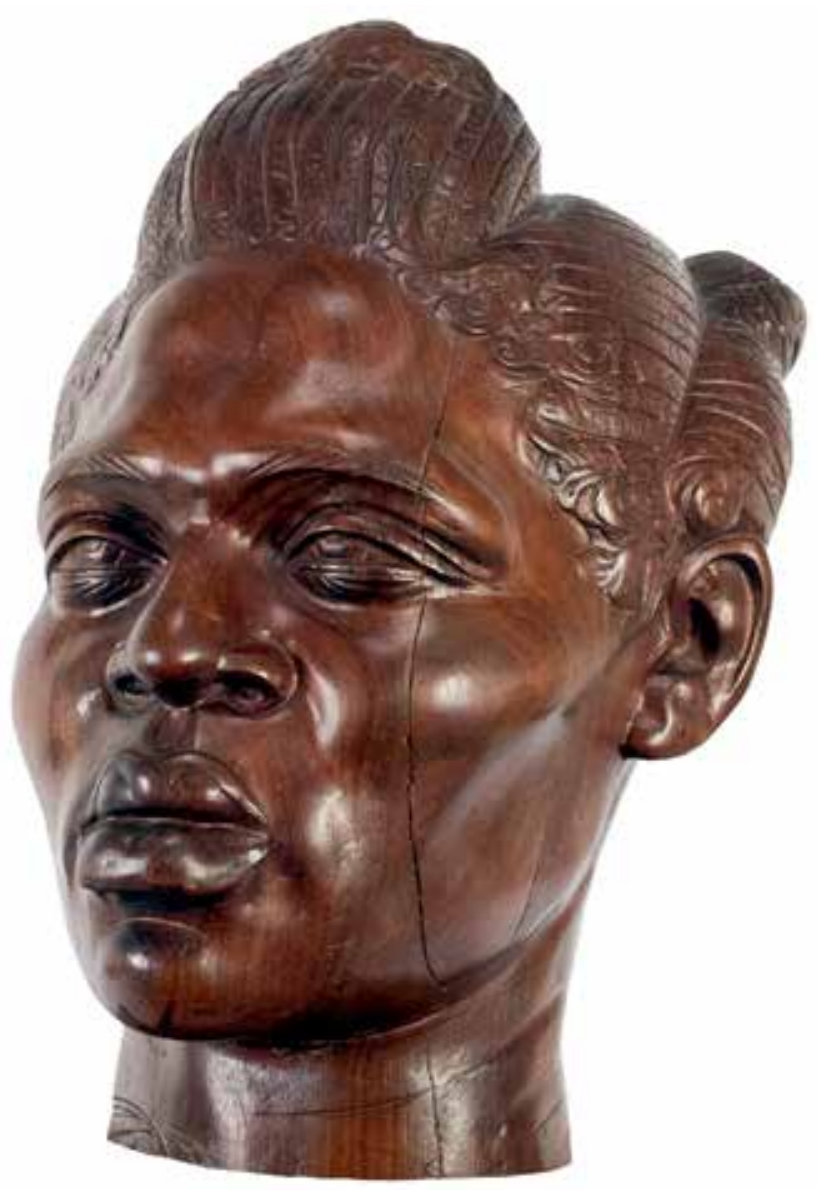

La noción de inconsciente colonial es pertinente para dimensionar la intervención estructurada y prolongada en el tiempo de estos modelos hegemónicos de estética, que afectan al propio cuerpo y la proyección política del mismo en diversos niveles. Según Rolnik este inconsciente colonial es "la política del inconsciente propio de Europa Occidental, de la cual nosotros, del llamado Sur, formamos parte, ya que fuimos fundados en este contexto, nuestro origen viene de ahí. Corresponde al modo de producción del deseo en el capitalismo mundial integrado" (Fernández y Pradel, 2015).

En este sentido, historizar a estos cuerpos nos permite abrir paso a una reflexión sobre las relaciones de la corporalidad con la ciudadanía y la ideología en los Estados. La obra de Rozo, presentada en las páginas anteriores, como se mencionó fue el momento clave para la constitución del Bachueísmo. Su estudio da cuenta de la temporalidad presente en la obra, que acopia el relato mitológico de la diosa chibcha, las partes del tronco demarcan en primer lugar: su no linealidad temporal definible, el lado superior denota el momento inicial de surgimiento de las aguas de Iguaque, y las piernas su transformación en serpiente cuando ve su tarea de poblar al mundo cumplida; en segundo lugar,
Imagen 4. Cabeza de negra. (Hena Rodríguez Parra, 1945). Madera, $30 \times 26 \times 21 \mathrm{~cm}$. Fuente: ARCADIA - periodismo cultural, No. 129 (28 de junio de 2016). en una sola materialidad, la de Bachué como diosa, coexisten representados varios organismos vivientes: la madre, el hijo, la serpiente en que deviene así como también la simbología muisca que porta.

Otra de las integrantes de los Bachué, Hena Rodríguez Parra, es rescatada desde el ámbito de lo corporal, sin abordar directamente la cuestión racial, ni originaria en su sentido convencional. Desde la pintura hasta su posterior transición a la escultura, esta artista posiciona imágenes disruptivas para la época:

Frente a los trabajos de esta artista, que se ha destacado también en genealogías recientes, el cuerpo transita entre lugares como la (auto) representación y la apuesta por cargar al cuerpo como un lugar de producción de saberes subjetivos, pero que para nada se limitan a ser meras sensaciones aisladas de un contexto.

En ambos casos, aparte de la expresividad corporal que dilucida una relacionalidad con una exterioridad, se visibilizan subjetividades no hegemónicas aún en la actualidad. 


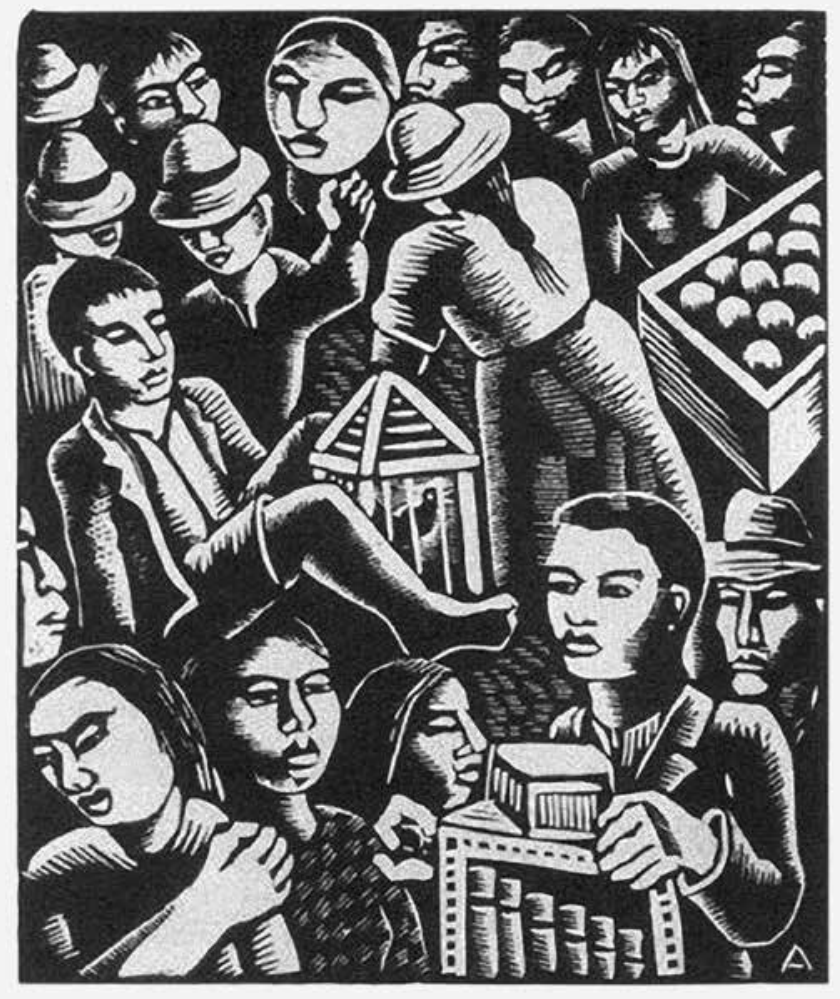

La apertura al género indeterminable en su totalidad, la androginia presente en la imagen; o la visibilización del no mestizaje, la pervivencia de rasgos explícitamente racializados de la afrodiáspora, son elementos que suscitan la compleja corporalidad que la obra de Rodríguez constituye. Pensar que esta visibilización, o representación de realidades no contadas si se quiere, pudiera llegar a tener mayor relevancia en las artes, permite especular la presencia visual (la circulación en diversos ámbitos) de estas corporalidades como un acto performativo, y reconocer el caso opuesto de la invisibilidad como performatividad con repercusiones ópticamente políticas que instaura modos de representación hegemónicos.

La performatividad de la visibilidad puede ser entendida como proyecto riguroso que oscila entre lo estético y lo político, que no es un acto único, sino "una repetición y un ritual que consigue su efecto a través de su naturalización en el contexto de un cuerpo, entendido, hasta cierto punto; como una duración temporal sostenida culturalmente" (Butler, 2007). En este sentido, el ocultamiento de este tipo de cuerpos al interior del canon del arte nacional encaja con los proyectos de instauración de una cultura afirmativa con pretensiones y miradas específicas sobre los cuerpos, así como la instauración
Imagen 5. Adoración del Santo Cristo de Viracachá. (Luis Alberto Acuña, 1945). Carbonillo, pastel y tiza sobre tela, 120 × $80 \mathrm{~cm}$. Fuente: http://www.banrepcultural.org/coleccion-de-arte-bancode-larepublica/obra/el-santo-cristo-de-barichara

y estructuración de miradas coloniales sobre y desde los cuerpos que "conforman" la nación.

La obra de Hena Rodríguez se intersecta de manera potente con el bachuísmo: sin caer en espacios esencialistas de lo nacional, de lo primigenio o de la "reconstrucción cultural" trata la visibilidad de los cuerpos que no responden a estas lógicas universalistas y coloniales, desde la materialidad misma del cuerpo y los afectos que puede producir como experiencia de sujeto (cuando se elabora un trabajo de construcción de sentido partiendo del bagaje cultural o las experiencias identitarias individuales) o fuera-del-sujeto (Rolnik, 2015), esto es, como lugar de interpelación de la mirada hegemónica construida sistemáticamente a partir del reconocimiento de una experiencia construida que excede el bagaje cultural y el sentido totalizante a partir de la experiencia individual, un lugar que oscila entre la no representación o no discursividad y que se potencia de la experiencia del continuo entre el cuerpo "propio" y el mundo.

Se potencia aquí algo así como lo que Martin Jay denominaría un "vistazo", una proyección e interpretación erigida a partir del deseo y no necesariamente ligada a una lógica cartesiana de la mirada que vincula al propio cuerpo a nivel experiencial. Esto coincide también con la mirada fenomenológica de Merleau-Ponty, para quien 


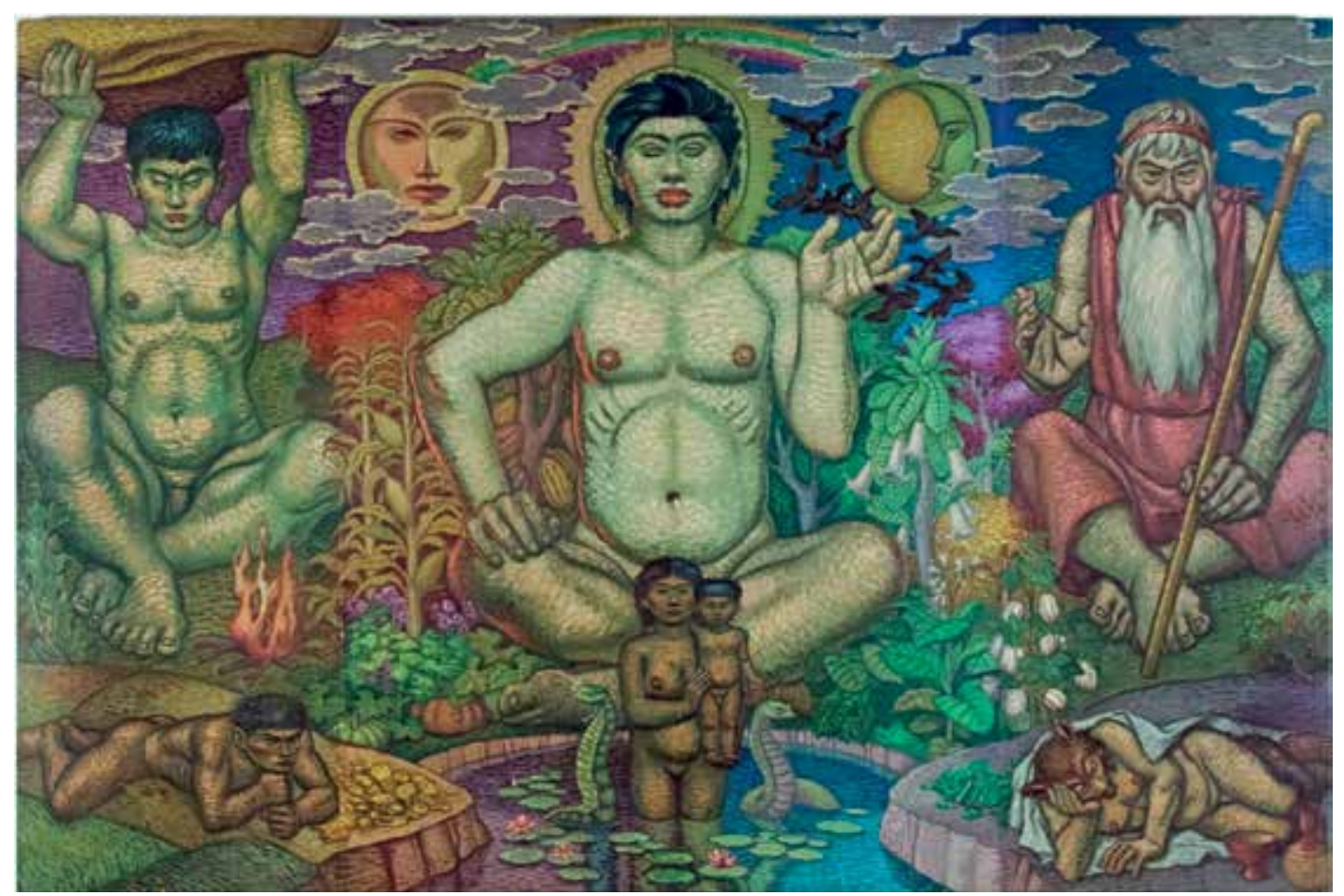

Imagen 6. Los dioses tutelares de los Chibchas. (Luis Alberto Acuña, 1938). Óleo sobre madera. $200 \times 300$ cm. Fuente: Colección del Museo Nacional de Colombia.

el "yo" se presenta como "encarnación dentro de la naturaleza" siendo la visibilidad del cuerpo la causante del reconocimiento de la alteridad. Cuando hablamos de intersubjetividad en Merleau-Ponty, debemos referirnos más bien a intercorporalidad o coexistencia (Foschi, 2013, p. 14); pues se potencia la posibilidad de reconocer el carácter compartido de la experiencia del mundo con otras subjetividades y corporalidades, el mismo "tejido sólido" al que llamamos realidad.

Me interesa hacer énfasis en que estas obras compartidas e interpretadas nos llaman la atención sobre la experiencia que la subjetividad tiene del mundo es mucho más amplia y más compleja: “Hay otra dimensión de la experiencia que la subjetividad hace del mundo, que llamo el «afuera-del-sujeto»; es la experiencia de las fuerzas que agitan el mundo como un cuerpo vivo que produce efectos en nuestro cuerpo" (Rolnik, 2015).

Finalmente, presento algunas de las obras de la prolífica producción artística de Luis Alberto Acuña, pintor e investigador que dedicó buena parte de su trayectoria profesional a investigar sobre las artes producidas por los pueblos preexistentes a la Conquista, y a difundir sus interpretaciones y construcciones estéticas basadas en la historia disponible hasta el momento de algunos de esos pueblos. Acuña no formó parte explícita de la agrupación que elaboró los textos del Bachueísmo, pero se adscribió públicamente a la corriente y fue uno de los actores centrales en la polémica argumentativa entre los aliados del proyecto artístico/político frente a los ataques y descalificativos recibidos por parte las corrientes modernizantes de producción y crítica artística. ${ }^{3}$

Las obras de este pintor buscan resaltar dos factores: por un lado, el legado mestizo de las culturas populares del país, un poco contrario a los intentos de una estética eugenésica (ejemplo en este texto con la pintura de Francisco A. Cano - Horizonte) que blanquea y homogeniza a la población, y que también oculta y subalterniza a partir de la no-representación de otros cuerpos. Este proyecto estético permite vislumbrar lo que Martin Jay retoma como la eidestética: El deseo de alcanzar la perfección poética del romanticismo que deriva en un proyecto en última instancia metafísico que también tiene implicaciones políticas. “La

$3 \quad$ El trabajo de Christian Padilla Peñuela, en su investigación
La Llamada de la tierra: el nacionalismo en la escultura colombiana
(2008), detalla minuciosamente la polémica desatada por la crítica de
Traba al trabajo realizado por el movimiento aquí estudiado y a poste-
riores artistas como Gonzalo Ariza que sintieron afinidad política y
estética frente a la labor de investigar y retomar herencias amerindias
en la producción estética nacional.




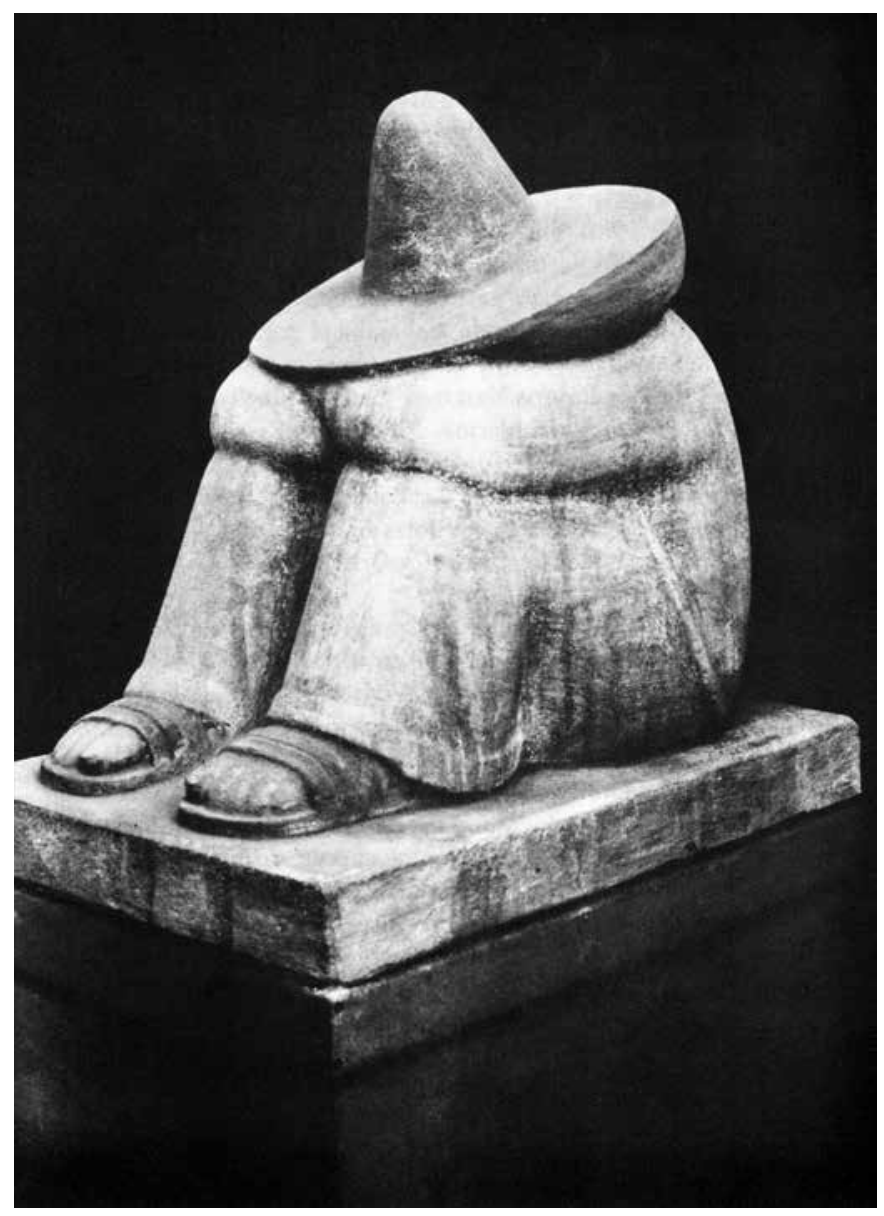

fascinación romántica por el fragmento, argumentan Lacoue-Labarthe y Nancy, parte de la premisa de que es posible la existencia de una "política ideal [...] una política orgánica" (2003, p. 151).

Justamente contra este fragmento de la realidad, la estética moderno/colonial, que blanquea la representación de los pueblos y sus corporalidades, es que la visibilización de estos pintores, como hitos del arte en Colombia, nos permite dimensionar lo que Ricardo Lambuley denomina la colonialidad estética de los sentidos, en donde el arte opera como un dispositivo de disciplinamiento mental y corporal (2011), así como en la naturalización de ideologías que clasifican lo visible por jerarquías constituidas a partir del legado eurocéntrico.

Marcuse demuestra que, en el orden burgués, esta reducción de lo estético (añadiendo ahora el legado colonial) produce una mutilación radical de la experiencia humana. En la exacta medida en la que el arte y el pensamiento teórico son enaltecidos como los puntos más altos de la praxis humana, la sociedad del trabajo y la productividad —que niega el tiempo libre a las clases
Imagen 7. El pensamiento. (Rómulo Rozo, 1932). Madera. Fuente: http://www.menendezymenendez.com/search/label/ FOTOGRAF\%C3\%8DAS\%20DP subalternizadas - relega la imaginación y el placer a la esfera de lo superfluo, despreciando casi por completo el valor cognitivo de la sensibilidad.

Sin embargo, la paradoja reside ahí, en que al mismo tiempo en el que se subvalora la sensibilidad, la cultura afirmativa proyecta hacia un plano superior todo aquello que la cotidianidad del capitalismo necesariamente excluye para su funcionamiento (Marcuse, 1978). El cuerpo, como representación, pero también como materialidad orgánica que constituye radicalmente la producción de subjetividad, se encuentra entonces en pugna frente a los proyectos de construcción de identidad nacional, entre modelos estético-políticos que lo desvirtúan como potencia productora de vida y conocimiento, reduciéndolo a una mera fuerza de trabajo. Estas posibilidades de traer al régimen de lo visible al cuerpo con otros tipos de relacionamientos contextuales y con la corporalidad misma, permite resignificar y transformar nuestros propios modos de ver(nos).

Por otro lado, Acuña también realizó un trabajo enorme orientado a la posibilidad de vislumbrar algunas de las 
cosmologías indígenas de los pueblos preexistentes a través de la rigurosa investigación histórica, arqueológica y etnológica disponible para la época, siendo Acuña uno de los grandes contribuyentes de mitad del siglo XX al estudio y recopilación tanto escrita como gráfica de muchas de las culturas indígenas, tanto de las que aún continúan habitando el territorio, así como algunas de las que solo se puede adentrar a partir de sus vestigios para intentar reconocer sus aportes y producciones tanto filosóficas como artísticas.

Las manifestaciones del cuerpo en este pintor destacan por su radical presencia del contexto que produce y posibilita a esos cuerpos en tanto materialidad, desde el contexto colonial, religioso, cotidiano en el que ubica a sus personajes mestizos, hasta el contexto mítico, relacional con la naturaleza en donde el cuerpo fluye en indeterminadas vías con la totalidad del territorio.

Continuando con una interpretación fenomenológica desde Merleau-Ponty: "el mundo está ahí" antes de cualquier reflexión siendo el hombre parte del entretejido de la naturaleza, "el hombre está investido en las cosas, y éstas investidas en él" (Merleau-Ponty, 2003, p. 31). La relación que las personas poseen con el mundo es una relación existencial, precomprensiva que hace del cuerpo su correlato perceptivo. Dice este pensador: "visible y móvil, mi cuerpo está en el número de las cosas, es una de ellas, pertenece al tejido del mundo, y su cohesión es la de una cosa" (Merleau-Ponty, 1986, p. 17).

\section{Recapitulando}

La perspectiva del cuerpo que se construye desde estos artistas reunidos por la cuestión de lo "propio", del pasado colectivo y de la crítica al asimilacionismo cultural, nos permite pensar y potenciar las miradas sobre los cuerpos racializados, desmitificados y fragmentados que son producto de una mirada universalista construida desde lugares hegemónicos y legitimada por la institucionalidad del proyecto estético moderno/ colonial.

Retomando los aportes de Marcusse sobre la proyección política de una cultura burguesa que se proyecta como neutral, se presenta al individuo en abstracto como portador de una nueva exigencia de felicidad. Debe él mismo hacerse cargo del cuidado de su existencia, de la satisfacción de sus necesidades. La liberación burguesa del individuo significa la posibilitación de una nueva felicidad. Pero con esto desaparece inmediatamente su validez universal ya que la igualdad abstracta de los individuos se realiza en la producción capitalista como la desigualdad concreta.

La visión burguesa de la nación, se veía reflejada en los proyectos estéticos hegemónicos que hasta hoy creen en la tradición occidental como la única fuente fidedigna de tratar y materializar lo bello, siendo otras construcciones, como la bachuísta, en principio un simple rezago de herencias tribales. Sin embargo, la existencia y la visibilización de otras formas de concebir estéticamente el cuerpo y reconocerlo también como un entramado de relaciones con el mundo, la vida y la naturaleza, permite desestabilizar y generar aperturas tanto de pensamiento como hacia lo sensible.

Terminaré este texto con un relato sobre la obra de Rómulo Rozo, quién se radicó en México después de consolidar su trayectoria artística. Allí pudo producir una serie de obras que resaltaron el proceso revolucionario así como la consolidación de la Nación mexicana, de nuevo retomando y valorizando el legado indígena y mestizo de esta nación.

La obra El Pensamiento, en palabras de Rozo, buscó proyectar el momento de necesaria reflexión de los mexicanos después de la lucha revolucionaria de inicios de siglo XX, también haciendo alusión al canon occidental (El Pensador de Rodin), sin embargo, la obra se popularizó por una apropiación caricaturezca y degradante en donde trazaban una bebida alcohólica al frente de la estatua, imagen fetichizada que representaba estereotipos racistas y xenófobos del mexicano perezoso y alcohólico.

Esta apropiación peyorativa de la obra podemos leerla como el permanente riesgo de cooptación y resignificación desde una óptica hegemónica de los proyectos de producción estética y política que desvelen la violencia y la dominación moderno/coloniales o que reivindiquen otros modos de ver (desde otras miradas o potenciando el surgimiento de nuevas perspectivas) que desnaturalizen las jerarquías arbitrarias instauradas sobre los cuerpos y sobre las vidas.

Sin embargo, este carácter no definitorio, abierto e incierto que se manifiesta ante este nuevo reparto de lo sensible, nos dice que no hay una visión teleológica de la historia que ubique de manera fatalista y definitiva la posibilidad de crear y producir perceptos y afectos que puedan desvirtuar el orden moderno/colonial que se 
ha logrado instaurar en el inconsciente colectivo de las múltiples sociedades latinoamericanas.

Retomar y revisitar el pasado, para pensar nuestros modos de ver los cuerpos que habitan y coexisten con nosotros, posibilita aperturas de ideas y de manifestaciones sensibles que permitan empezar con la ya anunciada tarea de descolonizar nuestra experiencia para poder dimensionar, en sus justas proporciones y carencias, lo que queremos ser como comunidades imaginadas, pasando por replantear la vigencia de lo nacional como horizonte que aún habitamos, espacio en disputa estética y política, en tiempos donde la desterritorialización del capitalismo mundial integrado moviliza deseos fragmentarios y aislados de nuestra experiencia corporizada, territorializada y sensible del mundo.

\section{Referencias}

Achury Valenzuela, Darío (1930, Junio 15)."América y nosotros." en diario El Tiempo. p. 2

Braidotti, R. (2005). Metamorfosis. Hacia una teoría materialista del devenir. Madrid: Akal.

Butler, J. (2007). Sujetos de sexo/género/deseo. En El género en disputa, el feminismo y la subversión de la identidad. Barcelona: Paidós.

Foschi, M. L. (2013). Merleau-Ponty: El cuerpo como apertura al mundo teatral. Cuadernos de la Facultad de Humanidades y Ciencias Sociales, 43(junio 2013), pp. 11-18. Jujuy: Universidad Nacional de Jujuy.

Fernández, A.;¿ Pradel, A. (2015). Una conversación con Suely Rolnik, En Re-visiones, 5. Madrid: Universidad Complutense de Madrid. Recuperado de http://www. re-visiones.net/spip. php\%3farticle128.html
Jay, M. (2003). Campos de Fuerza. Entre la historia intelectual y la crítica cultural. Buenos Aires: Paidós.

Lambuley Alférez, R. (2011). Genios, músicas y músicos: Colonialidad de los sentidos o evangelización estética. Calle14: revista de investigación en el campo del arte, 5(6), pp. 56-65. Bogotá: Universidad Distrital Francisco José de Caldas.

Marcuse, H. (1978). Cultura y sociedad. Buenos Aires: Sur.

Merleau-Ponty, M. (1986). El ojo y el espíritu. Barcelona: Ediciones Paidós Ibérica S.A. . (2003). El mundo de la percepción. México: Fondo de Cultura Económica.

Padilla, C. (2008). La llamada de la tierra: El nacionalismo en la escultura colombiana. Bogotá: Fundación Gilberto Álzate Avendaño.

Pedraza, Z. (2010). "Perspectivas de los estudios del cuerpo en América Latina." En Scribano, O. y Lisdero, P. (Comps.) Sensibilidades en Juego: miradas múltiples desde los estudios sociales de los cuerpos y las emociones. Córdoba: CEA - CONICET.

Rivera Cusicanqui, S. (2018). Un mundo ch'ixi es posible. Ensayos desde un presente en crisis. Buenos Aires: Tinta Limón Ediciones.

Suescún, M. (2007). “Modernidad, cuerpo y política en Colombia (1930-1948)". En Pedraza, Z. (ed.) Políticas y estéticas del Cuerpo en América Latina. Bogotá: CESO.

Traba, M. (1958) Problemas del Arte en Latinoamérica. Revista Mito. 3(19), pp. 428-436. 